\title{
Moving towards universal health coverage: Strengthening the evidence ecosystem for the South African health system
}

\author{
C Mathews, ${ }^{1} \mathrm{PhD} ;$ A Goga, ${ }^{1} \mathrm{PhD} ;$ M Loveday, ${ }^{1,2} \mathrm{PhD} ;$ W Zembe, ${ }^{1} \mathrm{PhD} ;$ E Daviaud, ${ }^{1} \mathrm{MSc} ; \mathrm{N}$ Siegfried, ${ }^{3} \mathrm{PhD} ;$ S Lewin, ${ }^{1,4} \mathrm{PhD}$ \\ ${ }^{1}$ Health Systems Research Unit, South African Medical Research Council, South Africa \\ ${ }^{2}$ Centre for the AIDS Programme of Research in South Africa, Nelson R Mandela School of Medicine, University of KwaZulu-Natal, Durban, South Africa \\ ${ }^{3}$ Independent clinical epidemiologist, Cape Town, South Africa; and Alcohol, Tobacco and Other Drug Unit, South African Medical Research \\ Council, South Africa \\ ${ }^{4}$ Division of Health Services, Norwegian Institute of Public Health, Oslo, Norway
}

Corresponding author: C Mathews (catherine.mathews@mrc.ac.za)

\begin{abstract}
Health policy and systems research (HPSR) guides health system reforms and is essential for South Africa (SA)'s progress towards universal coverage of high-quality healthcare. For HPSR evidence to inform and strengthen health systems, it needs to flow efficiently between evidence producers, evidence synthesisers, evidence processers and disseminators and evidence implementors in an evidence ecosystem. A substantial body of evidence for health systems strengthening is generated in SA, and this informs national and international health system guidelines and guidance. In this manuscript, in celebration of the 50th anniversary of the SA Medical Research Council, we apply an evidence ecosystem lens to the SA health system, and discuss its current functioning in support of the achievement of a high-quality health system that is able to achieve universal health coverage. We use three case studies to describe successes, challenges and gaps in the functioning of the evidence ecosystem. The first case study focuses on using evidence to strengthen health-system governance and support for community health worker programmes. The second case focuses on managing the growing epidemic of drug-resistant tuberculosis, while the third case focuses on social protection, the child support grant and its impact on health. SA scientists are part of global initiatives to strengthen the health-systems evidence ecosystem, specifically through pioneering methods to synthesise evidence and produce evidence-informed guidelines to facilitate evidence use in health-system decision-making. SA institutes of health policy analysis facilitate involvement of evidence producers and synthesisers in the national health system policy-making process. A future priority is to further strengthen national initiatives to translate evidence into policy and practice and to sustain capacity for continuous technical support to health-systems policy development and implementation.
\end{abstract}

S Afr Med J 2018;109(11 Suppl 1):S8-S14. https://doi.org/10.7196/SAMJ.2019.v109il1b.14245

After the first democratic election in South Africa (SA) in 1994, there was a need to shift from a health system fragmented by race and spatial segregation designed to maintain 'white' economic prosperity and political domination ${ }^{[1]}$ to one that ensures that all people living in SA have equitable access to comprehensive health services. SA now has one public national health system comprising the National Department of Health $(\mathrm{NDoH})$, nine provincial health departments, and 52 health districts. Today, the national health system has a strong focus on reforms to strengthen primary healthcare (PHC), and is governed by an overall body, the National Health Council, which links provincial health departments with the national minister. ${ }^{[2]}$ Since 1994, the geographical accessibility of primary health clinics has improved, and $90 \%$ of the population now lives within 5 kilometers of a health facility. ${ }^{[2]}$ The health system has achieved important successes, most notably through vertical programmes such as those to identify, treat and care for people living with HIV/AIDS and TB. SA has the world's largest antiretroviral treatment (ART) programme, which has increased life expectancy and saved lives ${ }^{[3]}$ and also cut mother-to-child transmission of HIV from 25 - 30\% before 2001 to $1.4 \%$ in $2016 .^{[4]}$ SA was also an early adopter of novel TB diagnostics ${ }^{[5]}$ and is the first country in the world to roll out novel, less toxic and more effective TB therapeutics. ${ }^{[6]}$

The National Health Insurance (NHI) system, outlined in the White Paper of 2017, is a plan for fundamental healthcare and health systems reforms to achieve universal health coverage. ${ }^{[7]}$ The reforms entail major changes in financing, management and administrative systems, and service delivery organisation and structures. For instance, PHC is being 're-engineered', with delivery through district-based, school-based and ward-based services.

Despite the major achievements of the past 25 years, and ambitious plans for the future, the health system has deep-seated and cross-cutting weaknesses. The workforce in the publicly funded health service is under strain, with insufficient stewardship of human resources for health planning across the system, staff shortages (especially in rural and underserved areas) and an inadequate national information system to enable human resources for health planning to address inequities. ${ }^{[8]}$ At the delivery level, recurrent stockouts of essential medicines highlight the fragility of the medicine supply system. ${ }^{[9,10]}$ In addition, inadequate leadership, management and governance have resulted in a systemwide lack of accountability and a failure to implement policies and appropriately allocate resources. This, in turn, negatively impacts clinical competence, quality of care and safety for service users. ${ }^{[11,2]}$ An extreme consequence of these weaknesses is the deprivation of an individual's basic right to access to healthcare. ${ }^{[8,13]}$ The authors of the 2012 Lancet 'Health in South Africa' series cautioned that successful implementation of health reforms in SA could be constrained by poor administrative and managerial capacity of the state. ${ }^{[14]}$ This remains an important concern today.

For health policy and systems research evidence to inform and strengthen health systems, it needs to flow efficiently between 
evidence producers, evidence synthesisers, evidence processers and disseminators and evidence implementors in an evidence ecosystem. In this manuscript, in celebration of the 50th anniversary of the SAMRC, we apply an evidence ecosystem lens to the SA health system and discuss its current functioning in support of the achievement of a high-quality health system that is able to achieve universal health coverage (UHC). We present three case studies to describe successes, challenges and gaps in the functioning of the evidence ecosystem. These case studies are intended to highlight predominantly (but not exclusively) work in which the South African Medical Research Council (SAMRC) has invested. They are not intended to represent the work of the SA health policy and systems research (HPSR) community as a whole.

\section{The roles of health policy and systems research}

A health system refers to all activities with the primary purpose of promoting, restoring or maintaining health. Health systems are complex, with multiple levels of operation (macro, meso, and micro levels) involving a wide range of delivery platforms and organisations, and an even wider range of stakeholders. HPSR is defined as research that guides health system reforms and the organisation and delivery of care through two sets of actions: firstly, 'the identification of gaps in capacity, barriers to efficient functioning and effective performance of the health system and methods by which existing resources can optimally be utilised', and secondly, 'the design and evaluation of innovative interventions which can improve the outreach and quality of health services and reduce health inequities. ${ }^{\text {'[15] }}$ HPSR is thus an essential part of SA's progress towards a high-quality health system.

For HPSR evidence to inform and strengthen health systems, it needs to make its way through the related stages of the evidence ecosystem ${ }^{[16-18]}$ (Fig. 1). Up to date evidence, including global and local evidence, needs to flow efficiently between evidence producers (those conducting primary research); evidence synthesisers (those summarising the research into systematic reviews or evidence syntheses); evidence processors and disseminators (those producing evidence-informed decision products such as health systems guidance and policy briefs); and evidence implementors (those responsible for implementing evidence-informed decisions

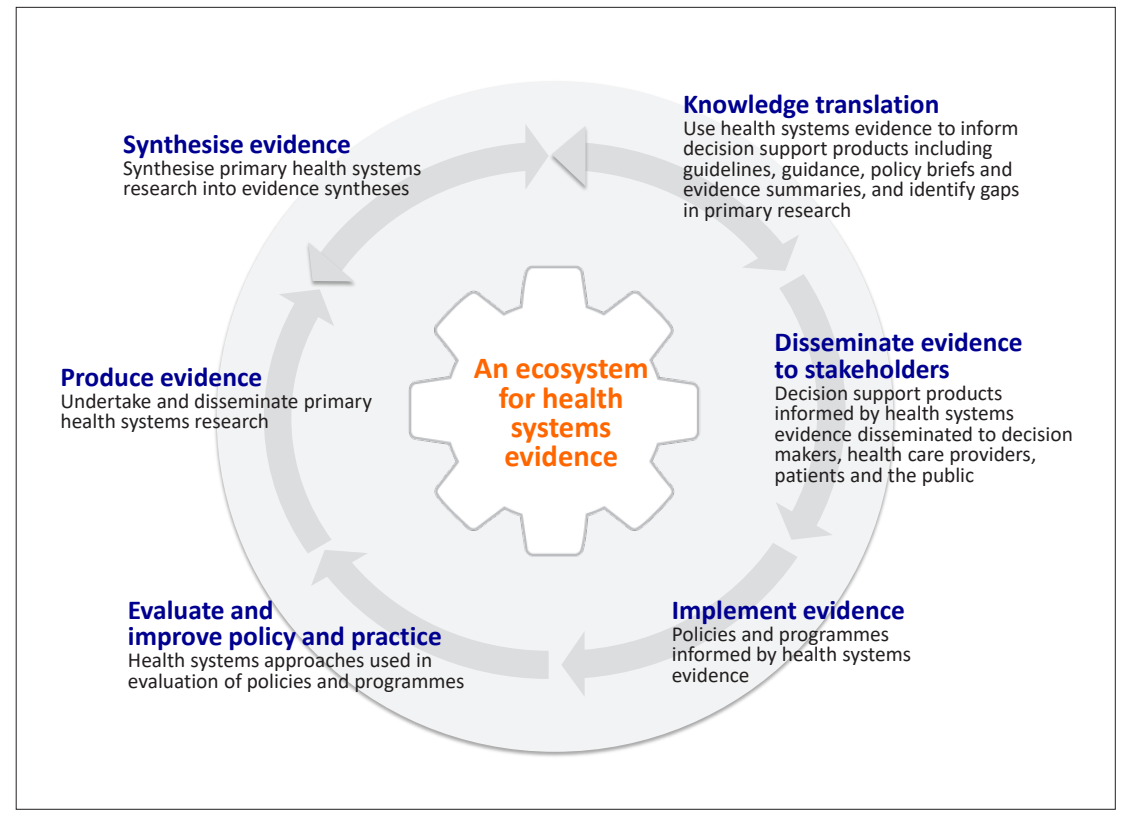

Fig. 1. The flow of evidence through health systems evidence ecosystem. (Adapted from: http:// magicproject.org/researchand-tools/the-evidence-ecosystem/)

within health systems, such as programme managers and policy makers, and those involved in delivering and using health services, such as service providers, and citizens). ${ }^{[17,18]}$ The purpose of the ecosystem is to sustain continuous evidence generation, synthesis and evidence-informed policy and practice. To achieve a flow of evidence and its translation into action, each stage needs to be connected, and at each stage there should be both demand for and supply of quality-assured evidence, together with a demand for evidence-informed decision products (evidence in usable forms) by evidence implementors. ${ }^{[19]}$ It has also been suggested that the flow of evidence through the ecosystem may be strengthened by the use of common or universal standards, such as terminologies for structuring effectiveness data and facilitating the open sharing of data, and by the wider use of stakeholder-friendly platforms for producing, finding and sharing evidence, such as Cochrane Review Manager $^{[20]}$ and GRADE evidence-todecision frameworks. ${ }^{[21,22]}$ Digital standards and tools that support the structuring and exchange of data between different parts of the evidence ecosystem and across technology platforms can also contribute to facilitating the efficient flow of evidence. ${ }^{[18]}$

Fig. 1 describes criteria for a wellfunctioning evidence ecosystem. The appropriate mix of types of evidence is determined by the policy issue being addressed and stage of the policy cycle. For example, qualitative evidence may be useful in understanding a health problem, such as why people do not take medications as prescribed. When assessing interventions or policy options for health systems, quantitative data derived from randomised trials provide evidence on effectiveness, while economic evidence answers questions about what resources are needed to achieve these benefits, and how these should be prioritised. Qualitative evidence can also provide insights into stakeholders' views of the acceptability and feasibility of these options. ${ }^{[1723]}$ Of course, policy making is not informed solely by global and local evidence, but also by competing social concerns and political and health system arrangements. ${ }^{[24,25]}$

\section{Case study 1: Using evidence to strengthen health system governance and support for community health worker programmes}

In $\mathrm{SA}$, community health workers (CHWs) are an integral part of ward-based PHC outreach teams, one of the four priorities of the NHI PHC re-engineering strategy. A large body of primary research on CHW programmes, including their governance, has been conducted in SA over several decades, making important contributions to the national and global bodies of evidence on this cadre. ${ }^{[44-48]}$ Several systematic reviews of the global evidence have been undertaken, including on the effectiveness of this cadre in improving child and adult health outcomes ${ }^{[49-51]}$ and on key barriers and facilitators to the 
successful and sustainable implementation of CHW programmes. ${ }^{[52]}$ These syntheses drew attention to the importance of appropriate support for CHWs from the health system and communities, as well as appropriate training and supervision, but also highlighted the challenges of ensuring meaningful community governance during implementation. ${ }^{[22,53]}$ This evidence was key to the development of a global World Health Organization (WHO) guideline on taskshifting for maternal and newborn health. ${ }^{[54]}$

To guide the optimal and efficient use of resources, the SA NDoH commissioned the SAMRC in 2017 to study the benefits and the costs of a well-functioning CHW programme. An investment case was prepared, drawing on evidence syntheses of the effects of CHWs on health outcomes, ${ }^{[5]}$ and provided information to the government on the expected return on investments in a CHW programme. The work noted that CHW interventions for maternal, neonatal and child health, HIV/AIDS, TB and diabetes would be highly cost-effective, and that $\mathrm{CHW}$ interventions for hypertension would be cost-effective. ${ }^{[56]}$ However, to yield these benefits $\mathrm{CHW}$ programmes need to be governed effectively. Our evidence synthesis of 21 systematic reviews found that very few primary studies and systematic reviews have evaluated governance arrangements for health systems in poorer countries, including for CHW programmes. Much of the available evidence comes from high-income countries with different on-the-ground realities and constraints, and different health systems arrangements, to SA, and may therefore not be directly relevant to our context. ${ }^{[57]}$

Drawing on leadership and governance conceptual frameworks from the social policy sector, and through primary research and case studies of provincial CHW programmes and the adoption and implementation of the wardbased outreach teams, SA scientists have now identified the key leadership and governance roles and the tasks required in reforming and governing national CHW programmes. ${ }^{[58-60]}$ This empirical work has been synthesised into a framework that systematises and organises the tasks of CHW programme governance, and serves as 'actionable' guidance for stewards of these programmes. ${ }^{[61]}$

\section{The evidence ecosystem (Fig. 2)}

This body of primary research has moved through the evidence ecosystem, contributing to both global systematic reviews and guidelines, with SAMRC researchers advising on the development of these guidelines. These global knowledge

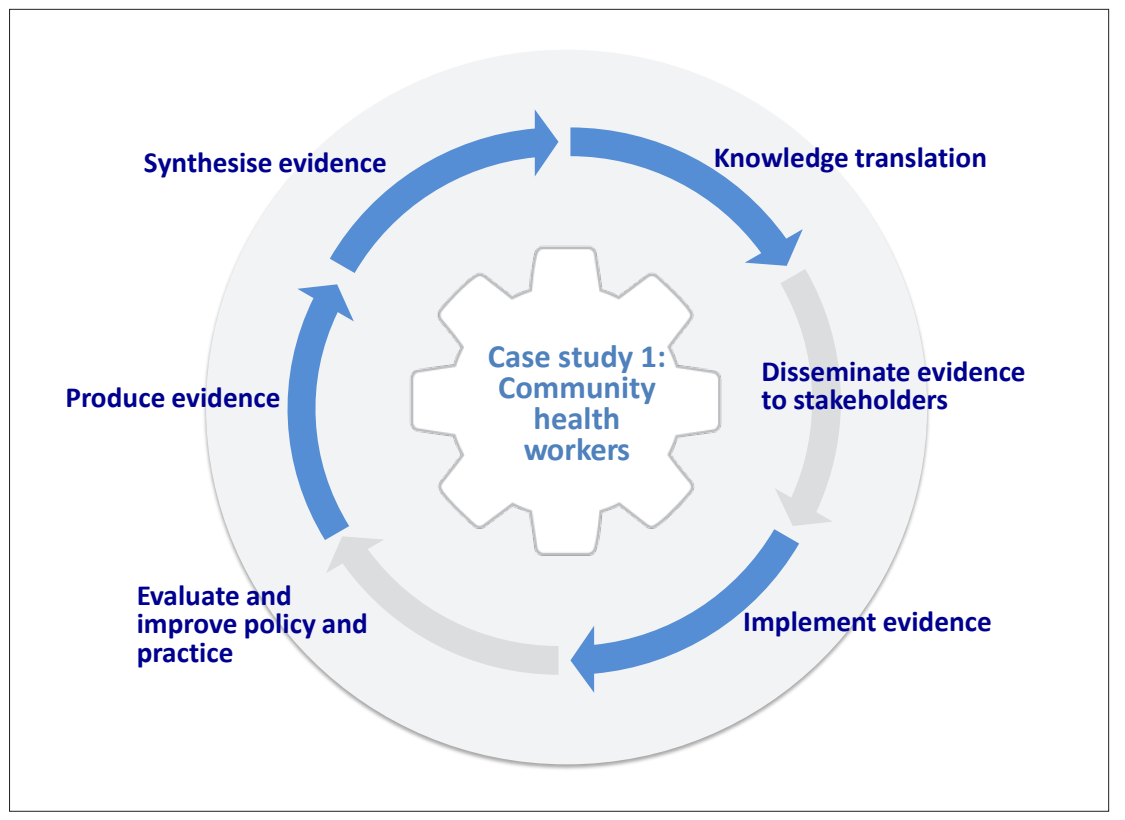

Fig. 2. Evidence ecosystem: Case study 1. (Adapted from: $h t t p: / / m a g i c p r o j e c t . o r g / r e s e a r c h a n d-$ tools/the-evidence-ecosystem/)

translation products are another route through which this evidence has flowed into policy implementation in SA. The review findings and guidelines were packaged into user-friendly products, including SUPPORT summaries, ${ }^{[62]}$ with the aim of facilitating the flow of evidence into policy processes. The case study also shows the importance of policy-maker 'pull' in relation to evidence, ${ }^{[63]}$ with the government commissioning the work on a $\mathrm{CHW}$ investment case. The $\mathrm{CHW}$ investment case was discussed with the Departments of both Health and Treasury. It informed the Department of Health's deliberations on the establishment of a national minimum wage for CHWs, and is being used to finalise the scope of $\mathrm{CHW}$ practice in SA.

\section{Case study 2: Managing the growing epidemic of drug-resistant tuberculosis}

SA has a growing burden of drug-resistant TB (DR-TB). ${ }^{[64]}$ Prior to 2008, the model of care in SA, aligned to WHO guidelines, was in-patient treatment at centralised, specialised hospitals for 6 months. Following discharge, and for the remaining period of treatment, patients were expected to return for monthly outpatient visits to the centralised hospital. However, the escalating burden of DR-TB and the limited availability of beds in specialised hospitals, as well as the difficulties experienced by people living with DR-TB in adhering to such treatment exigencies, led to delays in treatment initiation and poor treatment outcomes. ${ }^{[65]}$ It was clear that without decentralised, ambulatory models for DR-TB care, it would not be possible to achieve the required scale-up of rapid diagnosis and treatment. ${ }^{[66-68]}$

Contrary to the central recommendations in WHO guidelines at the time, ${ }^{[69]}$ models of decentralised DR-TB care were piloted and evaluated in SA. These evaluations showed higher cure rates and earlier treatment initiation, as well as better survival, compared with individuals treated in the centralised specialist hospital, ${ }^{[67,70-72]}$ and were more cost-effective. ${ }^{[73]}$ This locally relevant, timely evidence informed national policy on decentralised and deinstitutionalised management for DR-TB patients, and ultimately, WHO guidelines. ${ }^{[74]}$

Access to DR-TB care in KwaZulu-Natal Province has improved as a consequence of the decentralised model of DR-TB care, but evaluations of the implementation of the model have identified gaps and challenges. For example, primary evidence shows that DR-TB services are not always efficiently integrated into the district health system, ${ }^{[75,76]}$ universal TB infection control measures are not always implemented in health facilities ${ }^{[66]}$ and healthcare workers have been reported to discriminate against people with DR-TB. ${ }^{[77]}$

\section{The evidence ecosystem (Fig. 3)}

This case study illustrates that the flow through the evidence ecosystem is not unidirectional, and that local circumstances 
such as feasibility and burden of disease may influence the entry points into the flow. Innovation was required to test alternative models of DR-TB care when the contemporaneous WHO guideline did not meet SA's needs. Close working relationships between SA policy makers and those researchers generating local evidence about alternate models of care were key in facilitating the uptake of this evidence into local decision-making. This changed the way in which care for DR-TB is implemented in SA. This case study also illustrates the need for ongoing evaluation of national policy to identify barriers to successful implementation. This in turn drives primary health systems research.

\section{Case study 3: Social policy, health and the child support grant}

The health and wellbeing of populations depends largely on factors outside the health sector, ${ }^{[78]}$ such as poverty and deprivation, and the relationship between health and externally-derived social and economic problems is regarded as one of the greatest challenges facing health systems. ${ }^{[79]}$ Social policy, and social protection in particular, play a key role in improving health and wellbeing, ${ }^{[80,81]}$ and combinations of social protection (for example cash transfers, psychosocial care and support, educational support, housing, and water and sanitation) have been proposed as the most potentially effective approaches for health gain in SA. ${ }^{[82,83]}$ Evidence on these social policy interventions therefore needs to flow into the health systems evidence ecosystem.

The child support grant (CSG) is one of the SA government's key social protection instruments, and is the largest cash transfer programme on the African continent, currently reaching $\sim 12$ million children and targeting children aged $0-18$ years in poor households. Based on global syntheses that demonstrate the utility of cash transfers, ${ }^{[84-85]}$ primary research led by SA scientists and scientists from elsewhere shows that the CSG is an important policy instrument for tackling childhood poverty and improving child health and wellbeing. It can have positive impacts on child health and development outcomes, including child growth, hunger and school attendance and performance in the local context. ${ }^{[87]}$ However, about a fifth of children who meet the eligibility criteria for receiving the CSG do not access it, and evidence shows that the administrative barriers and the process of testing families for eligibility based on their income are the main obstacle to access. ${ }^{[88]}$ Through further primary research commissioned by the SA National Department of Social Development, local scientists have developed a financial model, the SA microsimulation model (SAMOD). SAMOD models the cost of increasing CSG access through a universal CSG that is funded via personal income tax, and the impacts that this would have on poverty. ${ }^{[89]}$
This evidence has the potential to inform future syntheses and policy on the design and implementation of the CSG in SA, as well as strengthen the intersectoral collaboration between departments responsible for ensuring CSG access.

\section{The evidence ecosystem (Fig. 4)}

This case study demonstrates how the concept of an evidence ecosystem is relevant

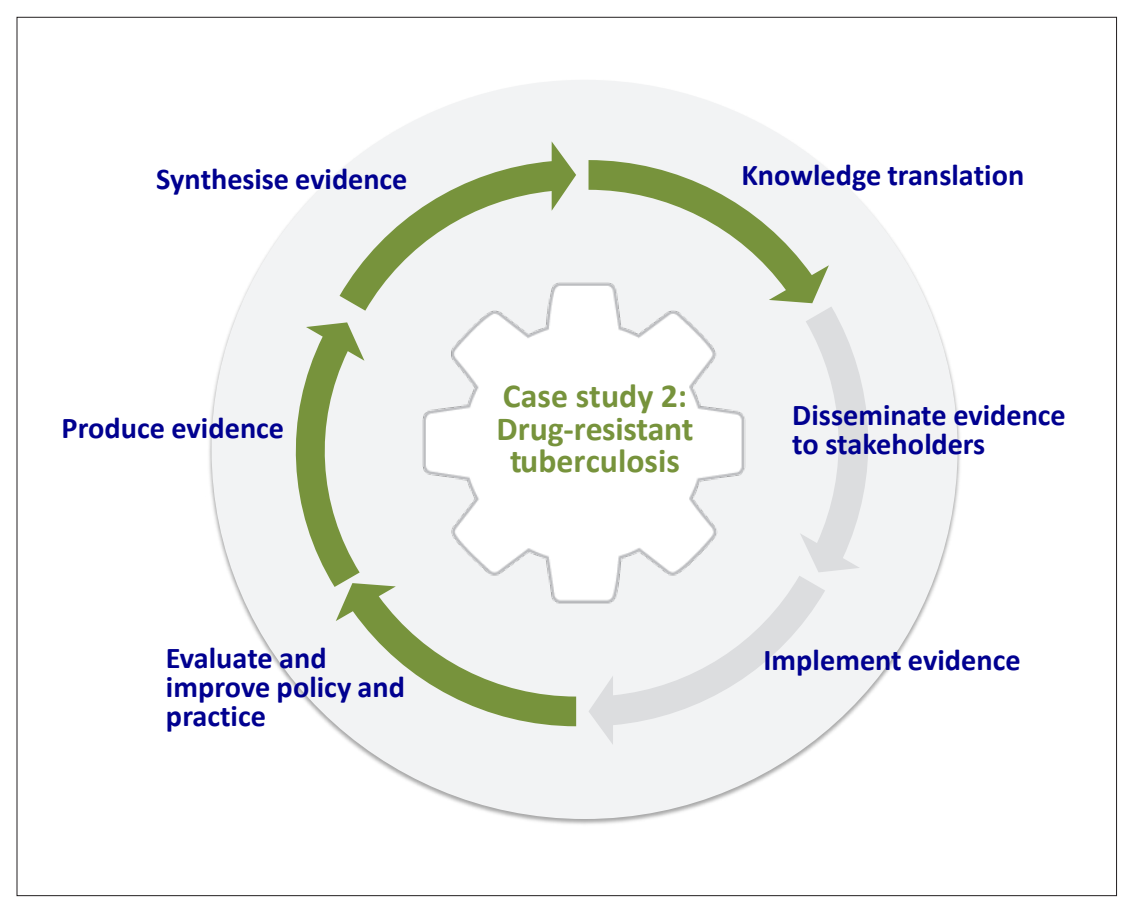

Fig. 3. Evidence ecosystem: Case study 2. (Adapted from: http://magicproject.org/researchand-tools/ the-evidence-ecosystem/)

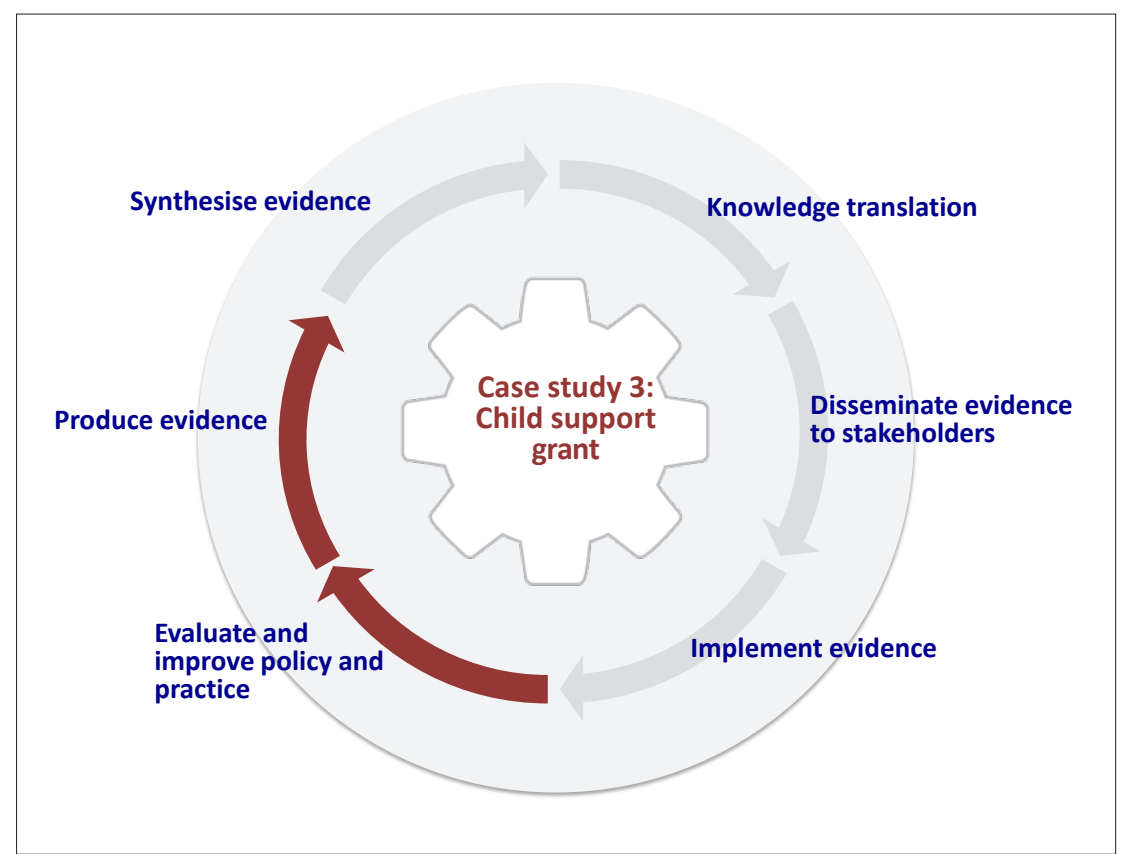

Fig. 4. Evidence ecosystem: Case study 3.(Adapted from: http://magicproject.org/researchand-tools/ the-evidence-ecosystem/) 
Table 1. Attributes of a well-functioning evidence ecosystem

Generation of relevant evidence

Timely, appropriate and relevant types of evidence are generated ${ }^{[19]}$ addressing the policy concerns at stake, including the multiple political considerations relevant to the decision, ${ }^{[26]}$ and the evidence is applicable in the local context. ${ }^{[27]}$ Evidence uses structured terminologies to facilitate retrieval and incorporation into evidence syntheses. ${ }^{[18]}$

Synthesis of evidence

A range of types of evidence is synthesised in an accessible way using systematic, rigorous, transparent methods. ${ }^{[28]}$ These syntheses include assessment of confidence in the evidence, using commonly accepted methods such as GRADE ${ }^{[29]}$ and GRADE-CERQual, ${ }^{[22,30]}$ and systematic identification of gaps in the evidence. Syntheses are conducted on platforms that facilitate data sharing across the evidence ecosystem, including through the use of structured terminologies and data. ${ }^{[18]} \mathrm{A}$ range of such digital platforms is now available, such as Covidence ${ }^{[31]}$ and Cochrane Review Manager. ${ }^{[20]}$

Processing of evidence

There is good governance of evidence ${ }^{[2]}$ through an independent quality assurance framework ${ }^{[19,32]}$ and systematic and transparent access to and appraisal of evidence as an input to the policy-making process. ${ }^{[24]}$ This should include a transparent process of declaring potential conflicts of interest, and public representation and deliberation in evidence-informed processes. ${ }^{[26]}$ Good governance of evidence can be enacted through international entities such as the WHO guidelines groups, Cochrane ${ }^{[33]}$ and national entities such as health policy analysis institutes or think tanks, ${ }^{[32,34]}$ or entities to develop policies and clinical practice guidelines. ${ }^{[35]}$ Evidence is processed on digital platforms such as GRADEpro ${ }^{[36]}$ and MAGICapp ${ }^{[37]}$ that facilitate data sharing across the evidence ecosystem and that use trustworthy standards and methods for decision support products such as clinical guidelines and health systems guidance. ${ }^{[38,39]}$

Dissemination of evidence

There are supportive structures to consolidate and disseminate evidence in useable forms with actionable recommendations for implementors. ${ }^{[19]}$ Digital platforms that link to other stages of the evidence ecosystem may facilitate evidence dissemination as well as feedback on evidence products. ${ }^{[18]}$ Producing and disseminating summaries of research findings with key actionable recommendations can contribute to the successful uptake of evidence. ${ }^{[34]}$ Recent advances in methods facilitate the use of qualitative evidence in evidence-informed decision products. ${ }^{[4]}$ Implementation of evidence

Many policy makers, health providers and citizens are able and eager to use the evidence. This is facilitated through dialogue and exchange between researchers and policy makers, ${ }^{[41,42]}$ by personal contacts between people operating in the various domains of the ecosystem, ${ }^{[34]}$ by demand-driven research where the policy makers or other stakeholders such as civil society commission research ${ }^{[15]}$ and through embedded research. ${ }^{[43]}$

not only to the health sector but also to other sectors, such as social policy. Close collaboration between policy makers and researchers, including the direct commissioning of research by the social policy sector from health researchers in this case, is a factor that can potentially facilitate the flow of evidence about increasing access to social protection through the evidence ecosystem and promote evidence use in decision-making. The CSG is conceptualised by the SA government as one component of a package of social protection interventions aimed at improving child health and wellbeing. Access to the other interventions that comprise the combination package will require collaboration between the social policy sector and, for example, the health, water and sanitation and other sectors. Evidence from multiple sectors will need to flow into this crosssectoral evidence ecosystem to inform these policies (Figs 2 - 4).

\section{Discussion}

The evidence ecosystem model for health systems illustrates how evidence needs to be transferred between different key stages to strengthen health systems and inform care. It shows the importance of 'closing the loop' between evidence producers, synthesisers, and disseminators and users. Figs 2 - 4 illustrate the functioning of the evidence ecosystem in relation to each of the three case studies.

The first case study considers the use of evidence to strengthen health systems governance, focusing on CHWs. Governance is a key foundational building block of a health system, ${ }^{[91]}$ and refers to the oversight and guidance that enables the whole system to function effectively. Evidence should play a critical role in informing governance arrangements for health systems. SA scientists play a leading role globally in developing an understanding of how to strengthen leadership and governance in health systems. ${ }^{[91-94]}$ This case study shows how, in relation to CHW programme governance, primary evidence is generated and synthesised, and how it informs health systems guidance and practice at international and national levels through knowledge translation processes. However, the case study also highlights critical gaps in the evidence base on governance arrangements for health systems, both in relation to the production of primary research on systems governance in poorer countries and in the synthesis of this evidence into systematic reviews. ${ }^{[57]}$ It is also not yet clear how the available evidence, including locally developed frameworks, is moving through the evidence ecosystem to implementors, including health service managers.

Case study 2 shows how international guidelines, such as the WHO guidelines on DR-TB care, need to be carefully evaluated in relation to the local context, with reference to health systems feasibility, cost and the burden of disease. This type of evaluation would be best done within a statutory health technology assessment (HTA) framework. HTA is defined as the systematic evaluation of properties, effects and/or impacts of health technologies and interventions', where technologies refer to any intervention, including pharmaceuticals, medical devices and also the broader organisation of the healthcare system. ${ }^{[32]}$ The absence of an HTA framework is one of the barriers to the good governance of evidence as it flows through the ecosystem to inform decision-making in SA. The $\mathrm{NDoH}$ is actively developing an HTA model to address this gap locally. At present, national think tanks, such as the TB Think Tank set up by the government National TB Programme, use evidence and policy dialogues to guide and support government in health systems policy development, and to guide the local research agenda. ${ }^{[95]}$ Think tanks have the potential to enhance the use of evidence to strengthen SA health systems and also provide opportunities for broader representation in the policy-making process, including from civil society organisations and citizens. In the absence of a statutory HTA-like entity, think 
tanks may require strengthening to sustain their capacity to provide continuous technical support and guidance to policy makers in SA. ${ }^{[95]}$ Further, they may need to build their mechanisms for governing evidence through transparent processes - they should be 'organisationally sound, scientifically credible institutions with some measure of autonomy. ${ }^{[34]}$

Case study 3 illustrates how the evidence ecosystem may need to extend beyond the health sector as multisectoral action is needed to address the social determinants of health. The limited co-ordination and integration between the SA national departments that are jointly responsible for providing access to grants - specifically, the Departments of Social Development, Health and Home Affairs limits implementation of and access to these evidence-informed interventions. ${ }^{[8]}$ This case study illustrates a critical gap in the production, synthesis and translation of evidence about combinations of interventions that transcend sectoral boundaries. Possible mechanisms for facilitating the flow of evidence on social protection through the evidence ecosystem include establishing a SA think tank for the social policy sector or putting in place a government entity with responsibility for developing intersectoral policy guidance across the health and social sectors.

\section{Conclusion}

Given the complexity of health systems, in practice there are multiple ecosystems of evidence that intersect at different levels of the health system and cross-sectoral boundaries. The ecosystem for health systems evidence needs to be conceptualised as global, and relevant evidence may be generated through studies undertaken at subnational, national or international levels ${ }^{[96]}$ and across sectors.

SA scientists are making critical contributions to building an evidence base for health systems strengthening globally and in SA, thereby supporting efforts to achieve UHC. We have shown how this policy-relevant evidence informs national and international health system guidelines and guidance. Furthermore, SA researchers and policy makers contribute to international knowledge translation fora and processes such as WHO guidelines processes. The outputs of these fora, in turn, inform SA health systems policies, thereby continuing the flow of evidence. SA health systems research scientists have been at the forefront of methodological advances for synthesising evidence, including evidence from qualitative studies, ${ }^{[17,97]}$ and for producing evidence-informed guidelines. ${ }^{[22,98-100]}$ A future priority is to strengthen national initiatives to make the evidence ecosystem function optimally. This will ensure that we grow and sustain a 'learning health system' in which policies, guidelines, programmes and decisions are informed by the best evidence, ultimately leading to a healthier population. ${ }^{[101]}$

Acknowledgements. We acknowledge the excellent research of the SA community of health policy and systems researchers including the contributions of scientists in SAMRC intramural and extramural research units over the past five decades. We would also like the acknowledge the MAGIC Evidence Ecosystem Foundation for their work in developing the 'Digital and trustworthy evidence ecosystem' model (http://magicproject. $\mathrm{org} /$ solutions/evidence-ecosystem/) - we have drawn extensively on this work, and the work of others in this area, in conceptualising this paper and in framing the case studies described.

Author contributions. SL and CM conceptualised the review. CM lead the writing and all authors contributed by writing sections of the review, and by reviewing drafts.
Funding. None.

Conflicts of interest. None.

Price M. Health care as an instrument of apartheid policy in South Africa. Health Policy Plann 1986;1(2):158-170. https://doi.org/10.1093\%2Fheapol\%2F1.2.158

2. World Health Organization. Primary Health Care Systems (PRIMASYS): Case Study from South Africa. Geneva: WHO, 2017. https://www.who.int/alliance-hpsr/projects/alliancehpsr_ southafricaabridgedprimasys.pdf?ua $=1$

3. Dorrington R, Bradshaw D, Laubscher R, Nannan N. Rapid Mortality Surveillance Report 2017. Cape Town: South African Medical Research Council, 2019. http://www.samrc.ac.za/sites/default/ files/files/2019-02-06/RapidMortalitySurveillanceReport2017.pdf (accessed 11 October 2019).

4. Goga A, Sherman G, Chirinda W, et al. Eliminating mother to child transmission of HIV in South Africa: 2002-2016, progress, challenges and the Last Mile Plan. In: Rispel LC, Padarath A, eds. South Af South African Health Review 2017. Durban: Health Systems Trust, 2017:137-146. https./www Af South African Health Review 2017. Durban: Health Systems Trust, 2017:137-146. https://www. hst.org.za/publications/South\%20African\%20Health\%20Reviews/13_Eliminating\% 20 mother\%20 to 20 child $\% 20$ transmission $\% 20$ of $\% 20 \mathrm{HIV} \% 20$ in $\% 20$ South\%20Africa_2002\%20to\%2020 progress_challanges\%20and\%20the\%20Last\%20Mile\%20Plan.pdf (accessed 11 October 2019).

. Churchyard GJ, Stevens WS, Mametja LD, et al. Xpert MTB/RIF versus sputum microscopy as the initial diagnostic test for tuberculosis: A cluster-randomised trial embedded in South African roll-out of Xpert MTB/RIF. Lancet Glob Health 2015;3(8):e450-e457. https://www.thelancet.com/ journals/langlo/article/PIIS2214-109X(15)00100-X/fulltext

6. Schnippel K, Ndjeka N, Maartens G, et al. Effect of bedaquiline on mortality in South African patients with drug-resistant tuberculosis: A retrospective cohort study. Lancet Resp Med 2018;6(9):699-706. https://doi.org/10.1016\%2Fs2213-2600\%2818\%2930235-2

7. National Department of Health $(\mathrm{NDoH})$. National Health Insurance Policy: Towards Universal Health Coverage. NDoH: Pretoria, 2017. http://www.health.gov.za/index.php/ nhi?download=2257: white-paper-nhi-2017 (accessed 11 October 2019).

8. Rispel L, Blaauw D, Ditlopo P, White J. Human resources for health and universal health coverage: 8. Rispel L, Blaauw D, Ditlopo P, White J. Human resources for health and universal health coverage:
Progress, complexities and contestations SAHR 2018. Durban: Health Systems Trust, 2018:13-21. Progress, complexities and contestations SAHR 2018. Durban: Health Systems Trust, 2018:13-21.
https://www.hst.org.za/publications/South\%20African\%20Health\%20Reviews/Chap\%202\%20 https://www.hst.org.za/publications/South\%20African\%20Health\%20Reviews/Chap

9. Hwang B, Shroufi A, Gils T, et al. Stock-outs of antiretroviral and tuberculosis medicines in 9. Hwang B, Shroufi A, Gils T, et al. Stock-outs of antiretroviral and tuberculosis medicines in
South Africa: A national cross-sectional survey. PLoS One 2019;14(3):e0212405. https://doi. org/10.1371\%2Fjournal.pone.0212405

10. Stop Stock Outs 4th National Survey Report (2017): The Fragile System 2017. https://sahivsoc.org/ FileUpload/Stop\%20Stockouts\%20National\%20Report\%20Oct\%202018.pdf (accessed 24 April 2019).

11. Rispel L. Analysing the progress and fault lines of health sector transformation in South Africa. South African Health Review, Health Systems Trust 2016:17-23. https://journals.co.za/content/ healthr/2016/1/EJC189322

12. Office of Health Standards Compliance. Annual Inspection Report 2016/17. Pretoria: OHSC, 2017. http://ohsc.org.za/wp-content/uploads/OHSC-2016-17-ANNUAL-INSPECTION-REPORTFINAL.pdf (accessed 11 October 2019)

13. South African Human Rights Commission. Report of the National Investigative Hearing into the Status of Mental Health Care in South Africa, 14 and 15th November 2017. Johannesburg: SAHRCH, 2019 https://www.sahrc.org.za/home/21/files/SAHRC\%20Mental\%20Health\%20 SAHRCH, 2019 https://www.sahrc.org.za/home/21/files
Report\%20Final\%2025032019.pdf (accessed 201924 April).

14. Mayosi BM, Lawn JE, van Niekerk A, Bradshaw D, Abdool Karim SS, Coovadia HM. Health in South Africa: Changes and challenges since 2009. Lancet 2012;380(9858):2029-2043. https://doi.org/10.10 16\%2Fs0140-6736\%2812\%2961814-5

15. World Health Organization. Changing mindsets: Strategy on health policy and systems research. Geneva: WHO, 2012. https://www.who.int/alliance-hpsr/alliancehpsr_changingmindsets_ strategyhpsr.pdf

16. Elliott $\mathrm{JH}$, Turner $\mathrm{T}$, Clavisi $\mathrm{O}$, et al. Living systematic reviews: An emerging opportunity to narrow the evidence-practice gap. PLoS Med 2014;11(2):e1001603. https://doi.org/10.1371/journal. pmed.1001603.

17. Lewin S, Glenton C. Are we entering a new era for qualitative research? Using qualitative evidence to support guidance and guideline development by the World Health Organization. Int $J$ Equity Health 2018;17(1):126. https://doi.org/10.1186\%2Fs12939-018-0841-x

18. The Evidence Ecosystem: Personalised eHealth Solutions. http://magicproject.org/research-andtools/the-evidence-ecosystem/

19. Shepherd J. How to achieve more effective services: The evidence ecosystem. Cardiff: What Works Network/Cardiff University; 2014. Available from: : http://www.scie-socialcareonline.org.uk/howto-achieve-more-effective-services-theevidence-ecosystem/r/a11G0000006z7vXIAQ.

20. Review Manager (RevMan) [Computer program]. Version 5.3. Copenhagen: The Nordic Cochrane Centre, The Cochrane Collaboration, 2014

21. 21 Alonso-Coello P, Schünemann HJ, Moberg J, et al. GRADE Evidence to Decision (EtD) frameworks: A systematic and transparent approach to making well informed healthcare choices. 1: Introduction. BMJ 2016;353:i2016. https://doi.org/10.1136/bmj.i2016

22. Moberg J, Oxman AD, Rosenbaum S, et al. The GRADE Evidence to Decision (EtD) framework for health system and public health decisions. Health Res Policy Syst 2018;16(1):45. https://doi. org/10.1186/s12961-018-0320-2

23. Lewin S, Glenton C, Lawrie TA.Qualitative Evidence Synthesis (QES) for Guidelines: Paper 2 Using qualitative evidence synthesis findings to inform evidence-to-decision frameworks and recommendations. Health Res Policy Plann 2019; 17:75. https://doi.org/10.1186/s12961-019-0468-4

24. Oxman AD, Lavis JN, Lewin S, Fretheim A. SUPPORT Tools for evidence-informed health Policymaking (STP) 1: What is evidence-informed policymaking? Health research policy and systems. 2009;7(Suppl 1):S1. https://doi.org/10.1186\%2F1478-4505-7-s1-s1

25. Getting Research into Health Policy and Practice. Bias in the use of evidence for policy: 'technical bias' and 'issue bias'. 2016. http://blogs.lshtm.ac.uk/griphealth/files/2016/11/GRIP-Health-Brief-2. pdf (accessed 11 October 2019).

26. Getting Research into Health Policy and Practice (GRIP-HEALTH). Conceptualising the good governance of evidence; GRIP-Health Brief 6. 2016. https://www.researchgate.net/publication/311717877 Conceptualising_the_good_governance_of_evidence (accessed 11 October 2019).

27. Getting research into health policy and practice (GRIP-HEALTH). What is good evidence for policy?

28. Donnelly CA, Boyd I, Campbell P, et al. Four principles to make evidence synthesis more useful for policy. Nature 2018:558(7710):361-364.

2. Guyatt GH, Oxman AD, Schünemann HJ, Tugwell P, Knottnerus A. GRADE guidelines: A new series of articles in the Journal of Clinical Epidemiology. J Clin Epidemiol 2011;64(4):380-382.

30. Lewin S, Glenton C, Munthe-Kaas H. Using qualitative evidence in decision making for health . Lewin S, Glenton C, Munthe-Kaas H. Using qualitative evidence in decision making for health
and social interventions: An approach to assess confidence in findings from qualitative evidence and social interventions: An approach to assess confidence in findings from qualitative evidence
syntheses (GRADE-CERQual). PLoS Med 2015;12(10):e1001895. https://doi.org/10.1371/journal, pynthes.1001895
pmed 
31. Covidence. Melbourne: Covidence. https://www.covidence.org/home (accessed 11 October 2019)

32. Siegfried N, Wilkinson T, Hofman $\mathrm{K}$. Where from and where to for health technology assessment in South Africa. South African Health Review. Durban: Health Systems Trust, 2017:41-48.

33. Mbuagbaw L, Zogo PO, Kredo T, et al. Cochrane Africa: A network of evidence-informed health-care Mbuagbaw L, Zogo PO, Kredo T, et al. Cochrane Africa: A network of evidence-informed health-care
decision making across sub-saharan Africa. Pan Afr Med J 2018;29:196. https://doi.org/10.11604\%2Fpa decision making across

34. Bennett S, Corluka A, Doherty J, et al. Influencing policy change: The experience of health think tanks in low- and middle-income countries. Health Policy Plann 2012;27(3):194-203. https://doi. org/10.1093\%2Fheapol\%2Fczr035

35. Kredo T, Abrams A, Young T, Louw Q, Volmink J, Daniels K. Primary care clinical practice guidelines in South Africa: Qualitative study exploring perspectives of national stakeholders. BMC Health Serv Res 2017;17(1):608. https://doi.org/10.1186\%2Fs12913-017-2546-z

36. GRADEPro. Hamilton, Canada: McMaster University and Evidence Prime Inc. https://gradepro.org/ (accessed 11 October 2019).

37. MAGICapp. Oslo, Norway: MAGIC Evidence Ecosystem Foundation. http://magicproject.org (accessed 11 October 2019).

38. Bosch-Capblanch X, Lavis JN, Lewin S, Atun R, Røttingen J-A, et al. Guidance for evidence-informed policies about health systems: Rationale for and challenges of guidance development. PLoS Med 2012;9(3):e1001185.

39. Brouwers MC, Ako-Arrey D, Spithoff K. Validity and usability testing of a health systems guidance appraisal tool, the AGREE-HS. Health Res Policy Syst 2018;16(1):51.

40. Lewin S, Bohren M, Rashidian A, et al. Applying GRADE-CERQual to qualitative evidence synthesis findings-paper 2: How to make an overall CERQual assessment of confidence and create a Summary
furcesting findings-paper 2: How to make an overall CERQual assessment of confidence and create a Summary
of Qualitative Findings table. Implement of Qualitative Findings

41. Young T, Shearer JC, Naude C, Kredo T, Wiysonge CS, Garner P. Researcher and policymaker dialogue: The Policy BUDDIES Project in Western Cape Province, South Africa. BMJ Glob Health 2018;3(6):e001130. https://doi.org/10.1136\%2Fbmigh-2018-001130

42. Oliver K, Innvar S, Lorenc T, Woodman J, Thomas J. A systematic review of barriers to and facilitators of the use of evidence by policymakers. BMC Health Serv Res 2014;14:2. https://doi. org/10.1186\%2F1472-6963-14-2

43. Ghaffar A, Langlois EV, Rasanathan K, Peterson S, Adedokun L, Tran NT. Strengthening health systems through embedded research. Bull World Health Organ 2017;95(2):87. https://doi. org/10.2471\%2Fblt.16.189126

44. Yach D, Hoogendoorn L, Von Schirnding YE. Village health workers are able to teach mothers how to safely prepare sugar/salt solutions. Paediatr Perinat Epidemiol 1987;1(2):153-161. https://doi. org/10.1111\%2Fj.1365-3016.1987.tb00105.x

45. Kuhn L, Zwarenstein M. Evaluation of a village health worker programme: The use of village health worker retained records. Int J Epidemiol 1990;19(3):685-692. https://doi.org/10.1093\%2Fije\%2F19.3.685

46. Kuhn L, Zwarenstein MF, Thomas GC, et al. Village health-workers and GOBI-FFF. An evaluation of a rural programme. S Afr Med J 1990;77(9):471-475.

47. Mathews $\mathrm{C}$, van der Walt $\mathrm{H}$, Barron P. A shotgun marriage - community health workers and government health services. Qualitative evaluation of a community health worker project in Khayelitsha. S Afr Med health services. Qualit

48. Nsibande D, Doherty T, Ijumba P, et al. Assessment of the uptake of neonatal and young infant referrals by community health workers to public health facilities in an urban informal settlement, KwaZulu-Natal, by community health workers to public health facilities in an urban informal settlement, KwaZ
South Africa. BMC Health Serv Res 2013;13:47. https://doi.org/10.1186\%2F1472-6963-13-47

49. Lewin S, Munabi-Babigumira S, Glenton C, et al. Lay health workers in primary and community health care for maternal and child health and the management of infectious diseases. Cochrane Database Syst Rev 2010;3:CD004015. https://doi.org/10.1002\%2F14651858.cd004015.pub3

50. Glenton C, Scheel IB, Lewin S, Swingler GH. Can lay health workers increase the uptake of childhood immunisation? Systematic review and typology.Trop Med Int Health 2011;16(9):1044-1053. https://doi. org/10.1111\%2F. $1365-3156.2011 .02813$.

51. Christopher JB, Le May A, Lewin S, Ross DA. Thirty years after Alma-Ata: a systematic review of the impact of community health workers delivering curative interventions against malaria, pneumonia and diarrhoea on child mortality and morbidity in sub-Saharan Africa. Human Resources Health 2011;9:27. https://doi.org/10.1186\%2F1478-4491-9-27

52. Glenton C, Colvin CJ, Carlsen B, et al. Barriers and facilitators to the implementation of lay health worker programmes to improve access to maternal and child health: Qualitative evidence synthesis. Cochrane Database Syst Rev 2013;10:CD010414

53. Gopinathan U, Lewin S, Glenton C. Implementing large-scale programmes to optimise the health workforce in low- and middle-income settings: A multicountry case study synthesis. Trop Med Int Health 2014;19(12):1437-1456. https://doi.org/10.1111\%2Ftmi.12381

54. World Health organization. WHO Recommendations: Optimizing Health Worker Roles to Improve Access to Key Maternal and Newborn Health Interventions Through Task Shifting. Geneva: WHO, 2012.

Access to Key Maternal and Newborn Health Interventions Through Task Shifting. Geneva: WHO, 2012. Database Syst Rev 2005;1:CD004015.

56. Daviaud E, Besada D, Budlender D, Sanders D. Saving lives, saving costs. Investment Case for Community Health Workers in South Africa. Cape Town: South African Medical Research Council; 2017. http://www mrc.ac.za/sites/default/files/files/2017-10-30/SavingLivesSavingCosts.pdf (accessed 11 October 2019).

57. Herrera CA, Lewin S, Paulsen E, et al. Governance arrangements for health systems in low-income countries: An overview of systematic reviews. Cochrane Database Syst Rev 2017;9:CD011085

58. Schneider H, Nxumalo N. Leadership and governance of community health worker programmes at scale: A cross case analysis of provincial implementation in South Africa. Int J Equity Health 2017;16(1):72.

59. Schneider H, Schaay N, Dudley L, Goliath C, Qukula T. The challenges of reshaping disease specific and care oriented community based services towards comprehensive goals: A situation appraisal in the Western Cape Province, South Africa. BMC Health Serv Res 2015;15:436. https://doi, org/10.1186\%2Fs12913-015-1109-

60. Lewin S, Lehmann U. Governing Community Health Worker Programs. In: Perry H, Grigler L, editors. Developing and Strengthening Community Health Worker Programs at Scale. Online report: http:// chwcentral.org/sites/default/files/MCHIP_CHW\%20Ref\%20Guide.pdf: MCHIP/USAID; 2014.

61. Schneider $\mathrm{H}$. The governance of national community health worker programmes in low- and middleincome countries: An empirically based framework of governance principles, purposes and tasks. Int J income countries: An empirically based framework of governance principles, purposes
Health Policy Management 2018;8(1):18-27. https://doi.org/10.15171\%2Fijhm. 2018.92

62. Flottorp S, Glenton C, Lewin S. Do lay or community health workers in primary healthcare improve maternal, child health and tuberculosis outcomes? A SUPPORT summary of a systematic review.
sumere https://supportsummaries.epistemonikos.org/support-summaries/show/do-lay-or-community-healthhttps://supportsummaries.epistemonikos.org/support-summaries/show/do-lay-or-community-health-
workers-in-primary-healthcare-improve-maternal,-child-health-and-tuberculosis-outcomesa (accessed workers-in-primary-he
11 October 2019)

63. Lavis JN, Lomas J, Hamid M, Sewankambo NK. Assessing country-level efforts to link research to action. Bull World Health Organ 2006;84(8):620-628. https://doi.org/10.2471\%2Fblt.06.030312

64. World Health Organization. Global tuberculosis report 2018. Geneva: WHO, 2018.

65. Wallengren K, Scano F, Nunn P, et al. Drug-resistant tuberculosis, KwaZulu-Natal, South Africa, 2001 2007. Emerg Infect Dis 2011;17(10):1913-1916. https://doi.org/10.3201/eid1710.100952

66. Van Cutsem G, Isaakidis P, Farley J, Nardell E, Volchenkov G, Cox H. Infection control for drug-resistant tuberculosis: Early diagnosis and treatment is the key. Clin Infect Dis 2016;62 Suppl 3:S238-243. https:// www.ncbi.nlm.nih.gov/pmc/articles/PMC4845888/
67. Cox H, Hughes J, Daniels J, et al. Community-based treatment of drug-resistant tuberculosis in Khayelitsha, South Africa. Int J Tuberculosis Lung Dis 2014;18(4):441-448. https://doi org/10.5588\%2Fijtld.13.0742

68. Cox H, Ford N. Decentralisation of multidrug-resistant tuberculosis care and management. Lancet Infect Dis 2013;13(8):644-646. https://doi.org/10.1016\%2Fs1473-3099\%2813\%2970151-8

69. World Health Organization. Guidelines for the programmatic management of drug-resistan tuberculosis. Geneva: WHO, 2006. https://books.google.co.za/books/about/Guidelines_for_the Programmatic_Manageme.html?id=XKsLs14_v4QC\&printsec=frontcover\&source=kp_read button\&redir_esc $=\mathrm{y} \# \mathrm{v}=\mathrm{onepage \& q} \& \mathrm{f}=$ false

70. Brust JC, Shah NS, Scott M, et al. Integrated, home-based treatment for MDR-TB and HIV in rural South Africa: an alternate model of care. Int J Tuberculosis Lung Dis 2012;16(8):998-1004. https://doi. org/10.5588\%2Fijtld.11.0713

71. Loveday M, Wallengren K, Voce A, et al. Comparing early treatment outcomes of MDR-TB in decentralised and centralised settings in KwaZulu-Natal, South Africa. Int I Tuberculosis Lung Dis 2012;16(2):209-215. https://doi.org/10.5588\%2Fijtld.11.0401

72. Loveday M, Wallengren K, Brust J, et al. Community-based care vs. centralised hospitalisation for MDRTB patients, KwaZulu-Natal, South Africa. Int J Tuberculosis Lung Dis 2015;19(2):163-171. https://doi. org/10.5588\%2Fijtld.14.0369

73. Loveday M, Wallengren K, Reddy T, et al. MDR-TB patients in KwaZulu-Natal, South Africa: Costeffectiveness of 5 models of care. PLoS One 2018;13(4):e0196003. https://doi.org/10.1371\%2Fjournal. pone. 0196003

74. World Health Organization. WHO consolidated guidelines on drug-resistant tuberculosis treatment. Geneva: WHO, 2019. https://www.ncbi.nlm.nih.gov/books/NBK539518/\#chl.s8 (accessed 19 May 2019).

75. Loveday M, Padayatchi N, Voce A, Brust J, Wallengren K. The treatment journey of a patient with multidrug-resistant tuberculosis in South Africa: Is it patient-centred? Tuberculosis Lung Dis 2013;17(10 Suppl 1):56-59.

76. Loveday M, Padayatchi N, Wallengren K, et al. Association between health systems performance and treatment outcomes in patients co-infected with MDR-TB and HIV in KwaZulu-Natal, South Africa Implications for TB programmes. PLoS ONE 2014;9(4):e94016.

77. Loveday M, Hlangu S, Furin J. Healthcare provider discrimination toward pregnant women with rifampin-resistant tuberculosis. Emerg Infect Dis 2019;25(3):609-610.

78. Braveman P, Gruskin S. Defining equity in health. J Epidemiol Community Health 2003;57(4):254-258.

79. UNRISD. Health Systems as Social Institutions: Progress towards Health in All Policies. United Nations Research Institute for Social Development, Programme Area: Social Policy and Development; 2015 http://www.unrisd.org/80256B3C005BB128/(httpProjects)/DB13A3F75C30A5B7C1257A1000576F5F (accessed day month year)

80. Ellis F, Devereux S, White P. Social Protection in Africa. Cheltenham: Elgar, 2009.

81. Hulme D, Hanlon J, Barrientos A. Just Give Money to the Poor The Development Revolution from the Global South; 2014. https://www.oecd.org/dev/pgd/46240619.pdf (accessed 11 October 2019).

82. Cluver LD, Orkin FM, Yakubovich AR, Sherr L. Combination Social Protection for Reducing HIV-Risk Behavior Among Adolescents in South Africa. J Acquired Immun Defic Syndr (1999). 2016;72(1):96-104. https://doi.org/10.1097\%2Fqai.0000000000000938

83. Zembe-Mkabile W, Surender R, Sanders D, et al. 'To be a woman is to make a plan': A qualitative study exploring mothers' experiences of the Child Support Grant in supporting children's diets and nutrition in South Africa. BMJ Open 2018;8(4):e019376. https://doi.org/10.1136\%2Fbmjopen-2017-019376

84. Siddiqi A, Rajaram A, Miller SP. Do cash transfer programmes yield better health in the first year of life? A systematic review linking low-income/middle-income and high-income contexts. Arch Dis Childhoo 2018;103(10):920-926. https://doi.org/10.1136\%2Farchdischild-2017-314301

85. Owusu-Addo E, Renzaho AMN, Smith BJ. The impact of cash transfers on social determinants of health and health inequalities in sub-Saharan Africa: A systematic review. Health Policy Plann 2018;33(5):675 696. https://doi.org/10.1093\%2Fheapol\%2Fczy020

86. Bastagli F, Overseas Development I. Cash transfers: What does the evidence say? A rigorous review of programme impact and of the role of design and implementation features. 2016. https://www.odi.org/ publications/10505-cash-transfers-what-does-evidence-say-rigorous-review-impacts-and-role-designand-implementation

87. Zembe-Mkabile W, Surender R, Sanders D, Jackson D, Doherty T. The experience of cash transfers in alleviating childhood poverty in South Africa: Mothers' experiences of the Child Support Grant. Global Pub Health 2015;10(7):834-851. https://doi.org/10.1080/17441692.2015.1007471

88. Zembe-Mkabile W, Doherty T, Sanders D, et al. Why do families still not receive the child support gran in South Africa? A longitudinal analysis of a cohort of families across South Africa. BMC internationa health and human rights. 2012;12:24. https://doi.org/10.1186\%2F1472-698x-12-24

89. Zembe-Mkabile W, Wright G, Noble M, McLennan D. Exploring options for financing a universal child benefit in South Africa using personal income tax. Presentation at: International Conference on Universal Child Grants; February, 2019; Geneva 2019.

90. World Health Organization. Everybody's business: Strengthening health systems to improve health outcomes. WHO's framework for action. Geneva: WHO, 2007. https://www.who.int/healthsystems strategy/everybodys_business.pd

91. Gilson L, Lehmann U, Schneider H. Practicing governance towards equity in health systems LMIC perspectives and experience. Int J Equity Health 2017;16(1):171. https://doi.org/10.1186\%2 Fs12939-017-0665-0

92. Cleary S, Toit AD, Scott V, Gilson L. Enabling relational leadership in primary healthcare settings: Lessons from the DIALHS collaboration. Health Policy Plann 2018;33(Suppl_2):ii65-ii74

93. Shung-King M, Gilson L, Mbachu C, et al. Leadership experiences and practices of South African health managers: what is the influence of gender? A qualitative, exploratory study. Int J Equity Health 2018;17(1):148.

94. Orgill M, Gilson L, Chitha W, Michel J, Erasmus E, Marchal B, et al. A qualitative study of the dissemination and diffusion of innovations: bottom up experiences of senior managers in three health districts in South Africa. Int J Equit Health 2019;18(1):53.

95. White RG, Charalambous S, Cardenas V, et al. Evidence-informed policy making at country level Lessons learned from the South African Tuberculosis Think Tank. Int J Tuberculosis Lung Dis 2018;22(6):606-613

96. Gilson L, Alliance for Health Policy and Systems Research, World Health Organization. Health policy and systems research: A methodology reader. Geneva: WHO, 2012

97. Lewin S, Booth A, Glenton C, et al. Applying GRADE-CERQual to qualitative evidence synthesis findings: Introduction to the series. Implement Sci 2018;13(Suppl 1):2.

98. Louw Q, Dizon JM, Grimmer K, McCaul M, Kredo T, Young T. Building capacity for development and implementation of clinical practice guidelines. S Afr Med J 2017;107(9):745-746.

99. Grimmer K, Dizon JM, Louw Q, Kredo T, Young T, Machingaidze S. South African Guidelines Excellence (SAGE): Efficient, effective and unbiased clinical practice guideline teams. S Afr Med J 2016;106(5):26-27.

100. Siegfried N, Draper B, Draper G, et al. A contextualisation approach to health promotion guideline development in South Africa. S Afr Med J 2018;108(12):1036-1041

101. Akhnif E, Macq J, Idrissi Fakhreddine MO, Meessen B. Scoping literature review on the Learning Organisation concept as applied to the health system. Health Res Policy Syst 2017;15(1):16. 